\title{
Nitric oxide acts as an antioxidant and delays methyl jasmonate- induced senescence of rice leaves
}

\author{
Kuo Tung Hung, Ching Huei Kao* \\ Department of Agronomy, National Taiwan University, Taipei, Taiwan, Republic of China
}

Received April 8, $2003 \cdot$ Accepted June 4, 2003

\begin{abstract}
Summary
In the present study, we evaluate the protective effect of nitric oxide (NO) against senescence of rice leaves promoted by methyl jasmonate (MJ). Senescence of rice leaves was determined by the decrease of protein content. MJ treatment resulted in (1) induction of leaf senescence, (2) increase in $\mathrm{H}_{2} \mathrm{O}_{2}$ and malondialdehyde (MDA) contents, (3) decrease in reduced form glutathione (GSH) and ascorbic acid (AsA) contents, and (4) increase in antioxidative enzyme activities (ascorbate peroxidase, glutathione reductase, peroxidase and catalase). All these MJ effects were reduced by free radical scavengers such as sodium benzoate and GSH. NO donors [ $\mathrm{N}$-tert-butyl- $\alpha$-phenylnitrone (PBN), sodium nitroprusside, 3-morpholinosydonimine, and $\mathrm{AsA}+\mathrm{NaNO}_{2}$ ] were effective in reducing MJ-induced leaf senescence. PBN prevented MJ-induced increase in the contents of $\mathrm{H}_{2} \mathrm{O}_{2}$ and MDA, decrease in the contents of GSH and AsA, and increase in the activities of antioxidative enzymes. The protective effect of PBN on MJ-promoted senescence, MJ-increased $\mathrm{H}_{2} \mathrm{O}_{2}$ content and lipid peroxidation, MJ-decreased GSH and AsA, and MJ-increased antioxidative enzyme activities was reversed by 2-(4-carboxy-2-phenyl)-4,4,5,5-tetramethyl-imidazoline-1-oxyl-3-oxide, a NOspecific scavenger, suggesting that the protective effect of PBN is attributable to NO released. Reduction of MJ-induced senescence by $\mathrm{NO}$ in rice leaves is most likely mediated through its ability to scavenge active oxygen species including $\mathrm{H}_{2} \mathrm{O}_{2}$.
\end{abstract}

Key words: active oxygen species - lipid peroxidation - methyl jasmonate - nitric oxide - Oryza sativa

Abbreviations: $A O S=$ active oxygen species. - APOD $=$ ascorbate peroxidase. - As $A=$ ascorbic acid. - CAT $=$ catalase. - c-PTIO = 2-(4-carboxy-2-phenyl)-4,4,5,5-tetramethylimidazoline-1-oxyl-3oxide. $-\mathrm{FW}=$ fresh weight. $-\mathrm{GR}=$ glutathione reductase. $-\mathrm{GSH}=$ reduced glutathione. $-\mathrm{MDA}=$ malondialdehyde. $-\mathrm{MJ}=$ methyl jasmonate. $-\mathrm{NO}=$ nitric oxide. $-\mathrm{PBN}=\mathrm{N}$-tert-butyl- $\alpha$-phenylnitrone. - POD = peroxidase. $-\mathrm{SB}=$ sodium benzoate. $-\mathrm{SIN}-1=3$-morpholinosydonimine. $-\mathrm{SNP}=$ sodium nitroprusside. - SOD $=$ superoxide dismutase

\footnotetext{
* E-mail corresponding author: kaoch@ccms.ntu.edu.tw
} 


\section{Introduction}

Jasmonic acid and its methyl ester, methyl jasmonate (MJ), collectively named jasmonates, have been proposed as naturally occurring plant growth regulators because of their wide natural distribution (Meyer et al. 1991) and their effects on many physiological processes in plants (Sembdner and Parthier 1993, Creelman and Mullet 1997, Wasternack and Parthier 1997). Jasmonates have been shown to be powerful promoters of leaf senescence (Ueda and Kato 1981, Weidhase et al. 1987, Chou and Kao 1992, Tsai et al. 1996, Chen and Kao 1998, Hung and Kao 1998). Recent molecular studies have confirmed that jasmonic acid may play a role in leaf senescence (He et al. 2002).

Lipid peroxidation is considered to be an important mechanism of leaf senescence (Thompson et al. 1987, Strother 1988). Active oxygen species (AOS) can initiate lipid peroxidation (Kellogg and Fridovich 1975). It has been shown that $\mathrm{MJ}$ causes the generation of $\mathrm{H}_{2} \mathrm{O}_{2}$ (Orozco-Cárdenas and Ryan 1999, Orozco-Cárdenas et al. 2001) and lipid peroxidation expressed as malondialdehyde (MDA) production in plant cells (Hung and Kao 1998). Thus, MJ leads to oxidative stress in plant cells.

Nitric oxide (NO) is a bioactive free radical implicated in a number of physiological functions, including intra- and intercellular mediation of some animal responses (Anbar 1995, Lamattina et al. 2003). NO is involved in many physiological responses of plants: pathogen response (Delledonne et al. 1998, Klessig et al. 2000, Orozco-Cárdenas et al. 2001), programmed cell death (Pedroso et al. 2000, Beligni et al. 2002), growth (Leshem and Haramaty 1996), germination (Beligni and Lamattina 2000), root organogenesis (Pagnussat et al. 2002), phytoalexin production (Noritake et al. 1996), interna iron availability (Graziano et al. 2002), salt and heat tolerance (Uchida et al. 2002), cytokinin action (Scherer and Holk 2000), abscisic acid-dependent stomatal closure (GarciaMata and Lamattina 2002, Neill et al. 2002), and ethylene emission (Leshem 2000).

Several reports convincingly demonstrate that $\mathrm{NO}$ is able to counteract the toxicity of paraquat and diquat, which are known to generate AOS, in potato and rice leaves (Beligni and Lamattina 1999 a, b, 2002, Hung et al. 2002), and block $\mathrm{H}_{2} \mathrm{O}_{2}$ production induced by jasmonic acid in tomato leaves (Orozco-Cárdenas and Ryan 2002). Thus, a possible participation of $\mathrm{NO}$ in the antioxidant system in plants, as observed in animals (O'Donnell et al. 1997, d'Ischia et al. 2000), is suggested. In rice leaves, it has been shown that NO donors reduced paraquat toxicity through a decrease in lipid peroxidation (Hung et al. 2002). More recently, we showed that the promotion of rice leaf senescence caused by abscisic acid, which induces $\mathrm{H}_{2} \mathrm{O}_{2}$ production and lipid peroxidation, can be counteracted by NO donors (Hung and Kao 2003). Jasmonates have both chemical and physiological similarities to abscisic acid (Anderson et al. 1989). It is logical to speculate that $\mathrm{NO}$ is also effective in counteracting MJ-induced senes- cence of rice leaves. In the present investigation, we examined the effect of $\mathrm{NO}$ on MJ-promoted senescence of rice leaves.

\section{Materials and Methods}

\section{Plant material and chemicals}

Rice (Oryza sativa L., cv. Taichung Native 1) was sterilized with $2.5 \%$ sodium hypochlorite for $15 \mathrm{~min}$ and washed extensively with distilled water. These seeds were then germinated in Petri dishes with wetted filter paper at $37^{\circ} \mathrm{C}$ under dark condition. After $48 \mathrm{~h}$ incubation, uniformly germinated seeds were selected and cultivated in a $500 \mathrm{~mL}$ beaker containing half-strength Kimura B solution as described previously (Chu and Lee 1989). The hydroponically cultivated seedlings were grown for 12 days in a Phytotron with natural light $30^{\circ} \mathrm{C}$ day $(12 \mathrm{~h}) / 25^{\circ} \mathrm{C}$ night $(12 \mathrm{~h}$ ) and $90 \%$ relative humidity. The apical $3 \mathrm{~cm}$ of the third leaf was used in all experiments. A group of ten segments was floated in a Petri dish containing $10 \mathrm{~mL}$ of test solution. Incubation was carried out at $27^{\circ} \mathrm{C}$ in the dark.

Test solutions included MJ, NO donors, a NO scavenger [2-(4-carboxy-2-phenyl)-4,4,5,5-tetramethylimidazoline-1-oxyl-3-oxide; C$\mathrm{PTIO}$, and free radical scavengers. PBN ( $\mathrm{N}$-tert-butyl- $\alpha$-phenylnitrone), 3-morpholino-sydonimine ( $\mathrm{SIN}-1)$ and sodium nitroprusside (SNP) were used as NO donors. We also used a solution containing ascorbic acid (AsA) and $\mathrm{NaNO}_{2}$ as another $\mathrm{NO}$ donor. Sodium benzoate (SB) and reduced glutathione (GSH) were used as free radical scavengers. All chemicals were purchased from Sigma Co. (St. Louis, MO, USA).

\section{Determinations of protein, $\mathrm{H}_{2} \mathrm{O}_{2}$, lipid peroxidation, GSH, and AsA}

The senescence of detached rice leaves was followed by measuring the decrease of protein content. For protein extraction, leaf segments were homogenized in $50 \mathrm{mmol} \mathrm{L}^{-1}$ sodium phosphate buffer $(\mathrm{pH} \mathrm{6.8)}$. The extracts were centrifuged at $17,600 \mathrm{~g}_{\mathrm{n}}$ for $20 \mathrm{~min}$, and the supernatants were used for determination of protein by the method of Bradford (1976) and enzyme activities. The $\mathrm{H}_{2} \mathrm{O}_{2}$ content was measured colorimetrically as described by Jana and Choudhuri (1981). $\mathrm{H}_{2} \mathrm{O}_{2}$ was extracted by homogenizing leaf tissue with phosphate buffer (50 mmol L-1 $\mathrm{pH} 6.5$ ) containing $1 \mathrm{mmol} \mathrm{L}^{-1}$ hydroxylamine. The homogenate was centrifuged at $6,000 \mathrm{gn}$ for $25 \mathrm{~min}$. To determine $\mathrm{H}_{2} \mathrm{O}_{2}$ content, the extracted solution was mixed with $0.1 \%$ titanium chloride in $20 \%(\mathrm{v} / \mathrm{v}) \mathrm{H}_{2} \mathrm{SO}_{4}$. The mixture was then centrifuged at $6,000 \mathrm{gn}_{\mathrm{n}}$ for $25 \mathrm{~min}$. The absorbance was measured at $410 \mathrm{~nm}$. The $\mathrm{H}_{2} \mathrm{O}_{2}$ content was calculated using the extinction coefficient $0.28 \mu \mathrm{mol}^{-1} \mathrm{~cm}^{-1}$. MDA, routinely used as an indicator of lipid peroxidation, was extracted with $5 \%(\mathrm{w} / \mathrm{v})$ trichloroacetic acid and determined according to Heath and Packer (1968). GSH in 3\% sulfosalicylic acid extract and AsA in $5 \%$ $(\mathrm{w} / \mathrm{v})$ trichloroacetic acid extract were determined as described by Smith (1985) and Laws et al. (1983), respectively.

\section{Enzyme assays}

Peroxidase (POD) activity was measured using a modification of the procedure of MacAdam et al. (1992). Activity was calculated using the extinction coefficient [26.6 $\left(\mathrm{mmol} \mathrm{L}^{-1}\right)^{-1} \mathrm{~cm}^{-1}$ at $470 \mathrm{~nm}$ ] for tetraguaia- 
col. Catalase (CAT) activity was assayed by measuring the initial rate of disappearance of $\mathrm{H}_{2} \mathrm{O}_{2}$ (Kato and Shimizu 1987). The decrease in $\mathrm{H}_{2} \mathrm{O}_{2}$ was followed as the decline in absorbance at $240 \mathrm{~nm}$, and activity was calculated using the extinction coefficient $\left[40\left(\mathrm{mmol} \mathrm{L}^{-1}\right)^{-1}\right.$ $\mathrm{cm}^{-1}$ at $240 \mathrm{~nm}$ ] for $\mathrm{H}_{2} \mathrm{O}_{2}$ (Kato and Shimizu 1987). Superoxide dismutase (SOD) was determined according to Paoletti et al. (1986). Ascorbate peroxidase (APOD) was determined according to Nakano and Asada (1981). The decrease in AsA concentration was followed as the decline in optical density at $290 \mathrm{~nm}$ and activity was calculated using the extinction coefficient $\left[2.8\left(\mathrm{mmol} \mathrm{L}^{-1}\right)^{-1} \mathrm{~cm}^{-1}\right.$ at $\left.290 \mathrm{~nm}\right]$ for AsA Glutathione reductase (GR) was determined by the method of Foster and Hess (1980). One unit of activity for CAT, POD, SOD, APOD, and GR was defined as the amount of enzyme which degraded $1 \mu \mathrm{mol}$ $\mathrm{H}_{2} \mathrm{O}_{2}$ per min, caused the formation of $1 \mu \mathrm{mol}$ tetraguaiacol per min, inhibited by $50 \%$ the rate of $\mathrm{NADH}$ oxidation observed in control, degraded $1 \mu \mathrm{mol}$ of AsA per min, and decreased $1 \mathrm{~A}_{340}$ per min respectively.

\section{Experimental design}

Protein, $\mathrm{H}_{2} \mathrm{O}_{2}, \mathrm{MDA}$, AsA, and GSH contents were expressed per $\mathrm{g}$ fresh weight (FW). Enzyme activities were expressed as unit $\mathrm{mg}^{-1}$ protein. In the present investigation, rice seedlings were grown for 12 days in a greenhouse, where natural light was provided. The growth of rice seedlings is very sensitive to light and varies with different light intensities. Experiments were carried out at different times of the year Thus, absolute levels of each measurement varied among experiments because of seasonal effects. However, the patterns of response to $\mathrm{MJ}$ and/or $\mathrm{NO}$ donors were reproducible. All measurements described here were repeated three times. Similar results and identical trends were obtained each time. The data reported here are from a single experiment.

\section{Results}

The obvious character of leaf senescence is yellowing. Chlorophyll loss has been considered to be the principal criterion of senescence. The protein breakdown during leaf senescence has been realized from earlier studies. We have shown that protein breakdown precedes chlorophyll loss during rice leaf senescence (Kao 1980). Thus, senescence of rice leaves in the present investigation was followed by measuring the decrease of protein. The changes in protein and MDA contents in detached rice leaves treated with $45 \mu \mathrm{mol} / \mathrm{L}^{-1}$ $\mathrm{MJ}$ in the dark are shown in Figures $1 \mathrm{~A}$ and $1 \mathrm{~B}$. The decrease in protein and increase in MDA were evident at day 1 after MJ treatment. Clearly, $\mathrm{MJ}$ is effective in promoting senescence of rice leaves. $M J$ treatment resulted in a marked increase in MDA, indicating that MJ brings about lipid peroxidation. Lipid peroxidation is caused by AOS (Kellogg and Fridovich 1975, Thompson et al. 1987). MJ treatment also caused an increase in $\mathrm{H}_{2} \mathrm{O}_{2}$ content (Fig. $1 \mathrm{C}$ ). In the present investigation, when free radical scavengers such as SB and GSH, were used together with $\mathrm{MJ}$, it was found that they partially inhibited the reduction in protein content (Fig. 2 A) and the increase in MDA
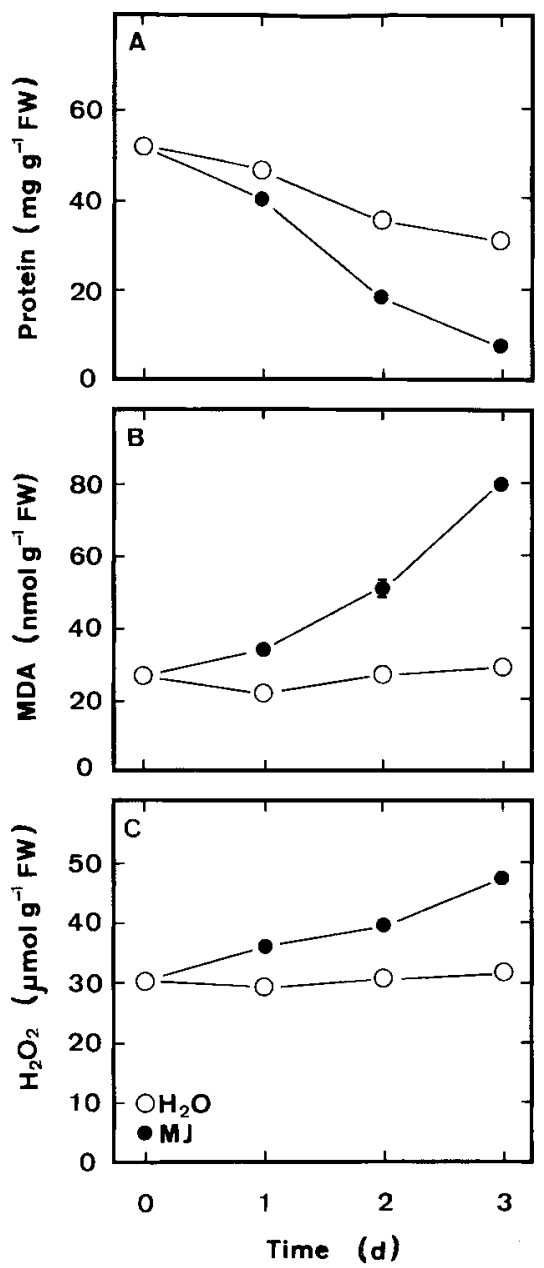

Figure 1. Changes in the contents of protein (A), MDA (B), and $\mathrm{H}_{2} \mathrm{O}_{2}$ $(C)$ in rice leaves treated with $\mathrm{MJ}$. Detached rice leaves were treated with either water or $45 \mu \mathrm{mol} \mathrm{L}{ }^{-1} \mathrm{MJ}$ in the dark. Data are means $( \pm \mathrm{SE})$ of four replicates of a single typical experiment. Three series of independent experiments were carried out giving reproducible results.

(Fig. $2 \mathrm{~B}$ ) and $\mathrm{H}_{2} \mathrm{O}_{2}$ (Fig. 2 C) contents caused by MJ. These results support the involvement of AOS as the chemical species inducing MJ-enhanced senescence in rice leaves.

Plant cells are equipped with several AOS detoxifying enzymes and antioxidants to protect them against oxidative damage. Antioxidative enzymes include SOD, APOD, GR, CAT, and POD (Foyer et al. 1997). AsA and GSH are two main water-soluble antioxidants (Foyer et al. 1997). The striking increase in lipid peroxidation seen in rice leaves treated with MJ may be a reflection of the change of the activities of antioxidative enzymes and the contents of antioxidants. As shown in Figures 3A, 3C, and 3D, MJ-treated rice leaves had higher activities of APOD, POD, and CAT than the controls at day 1 after dark incubation. Higher GR activity in MJ-treated rice leaves was observed only at 2 days after dark incubation (Fig. 3 B). But MJ treatment had no effect on SOD activity in 

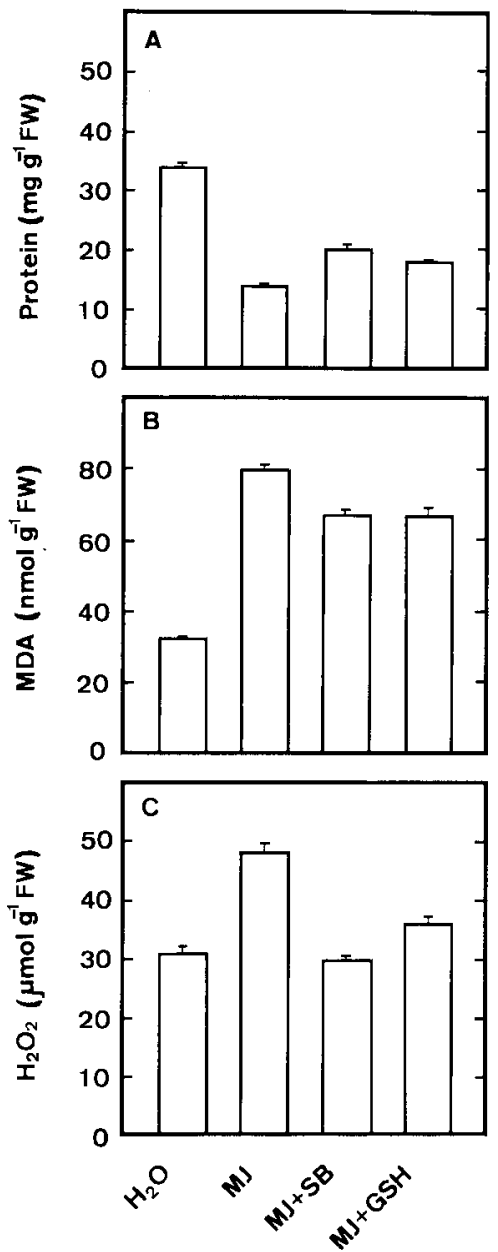

Figure 2. Effect of free radical scavengers (SB and GSH) on protein (A), MDA (B), and $\mathrm{H}_{2} \mathrm{O}_{2}(\mathrm{C})$ contents in rice leaves treated with $\mathrm{MJ}$. The concentrations of $\mathrm{MJ}, \mathrm{SB}$, and $\mathrm{GSH}$ were $45 \mu \mathrm{mol} \mathrm{L}^{-1}, 10 \mathrm{mmol} \mathrm{L}^{-1}$, and $30 \mathrm{mmol} \mathrm{L}^{-1}$, respectively. All measurements were determined 3 days after treatment in the dark. Data are means $( \pm \mathrm{SE}$ ) of four replicates of a single typical experiment. Three series of independent experiments were carried out giving reproducible results.

rice leaves (data not shown). Treatment with MJ significantly decreased AsA and GSH contents compared with the control leaves; it occurred at day 1 after treatment (Figs. 4A and 4B). The increased activities of antioxidative enzymes and the decreased contents of AsA and GSH in response to MJ further suggest a strong induction of oxidative stress. As expected, treatment with free radical scavengers (SB and $\mathrm{GSH}$ ) inhibited the increase in the activities of antioxidative enzymes (Figs. 5 A, 5B, and 5 C) and the decrease in the contents of AsA and GSH (Figs. 5D and 5E) in rice leaves caused by MJ.

We show that the promotion of senescence of detached rice leaves by $\mathrm{MJ}$ is linked to lipid peroxidation or oxidative stress. NO is known to counteract oxidative stress in plants (Beligni and Lamattina 1999 a, b, 2002, Beligni et al. 2002,
Table 1. Effect of NO donors on protein content in rice leaves treated with MJ.

\begin{tabular}{ll}
\hline Treatment & Protein $\left(\mathrm{mg} \mathrm{g}^{-1} \mathrm{FW}\right)$ \\
\hline $\mathrm{H}_{2} \mathrm{O}$ & $50.1 \pm 1.1$ \\
$\mathrm{MJ}$ & $38.1 \pm 0.21$ \\
$\mathrm{MJ}+\mathrm{PBN}$ & $47.2 \pm 0.91$ \\
$\mathrm{MJ}+\mathrm{SIN}-1$ & $43.7 \pm 0.11$ \\
$\mathrm{MJ}+\mathrm{SNP}$ & $42.9 \pm 0.73$ \\
$\mathrm{MJ}+\mathrm{AsA}+\mathrm{NaNO}_{2}$ & $41.8 \pm 0.18$
\end{tabular}

The concentrations of $\mathrm{MJ}, \mathrm{PBN}, \mathrm{SIN}-1, \mathrm{SNP}, \mathrm{AsA}$, and $\mathrm{NaNO}_{2}$ were $45,100,100,100,100$, and $200 \mu \mathrm{mol} \mathrm{L} \mathrm{L}^{-1}$, respectively. Protein content was determined 1 day after treatment in the dark. Data are means $( \pm \mathrm{SE})$ of four replicates of a single typical experiment. Three series of independent experiments were carried out giving reproducible results.

Cheng et al. 2002, Hung et al. 2002, Hung and Kao 2003). Thus, it is of great interest to know whether the protective role of $\mathrm{NO}$ is also active in MJ-promoted senescence of rice leaves. Consequently, detached rice leaves were treated with $\mathrm{MJ}$ in the presence or absence of NO donors, such as PBN, $\mathrm{SIN}-1, \mathrm{SNP}$, and a mixture of AsA and $\mathrm{NaNO}_{2}$ in the dark. As indicated in Table 1, all NO donors were effective in inhibiting MJ-promoted senescence of rice leaves. We also observed that $\mathrm{PBN}$ is more effective in inhibiting MJ-promoted leaf senescence than SIN-1, SNP, and AsA plus $\mathrm{NaNO}_{2}$ (Table 1).

PBN alone had no effect on protein content (Fig. 6). When applied together with MJ, PBN concentrations between 25 and $200 \mu \mathrm{mol} \mathrm{L}{ }^{-1}$ produced a clear protection against protein loss (Fig. 6). The optimal concentration of PBN in inhibiting MJ-promoted leaf senescence was observed to be $100 \mu \mathrm{mol}$ $\mathrm{L}^{-1}$ (Fig. 6)

To investigate whether the protective effect induced by $\mathrm{PBN}$ treatment was the result of the production of $\mathrm{NO}$, $100 \mu \mathrm{mol} \mathrm{L}{ }^{-1}$ C-PTIO, a NO-specific scavenger, was applied along with $100 \mu \mathrm{mol} \mathrm{L}^{-1} \mathrm{PBN}$. The effect of PBN on MJ-promoted protein loss (Fig. $7 \mathrm{~A}$ ) and increase in MDA and $\mathrm{H}_{2} \mathrm{O}_{2}$ contents (Figs. 7B and 7C) could be reversed by C-PTIO. We also observed that PBN counteracted MJ-induced increase of activities of antioxidative enzymes (CAT, POD and APOD) and C-PTIO reversed the effect of PBN-decreased enzyme activities (Figs. $8 \mathrm{~A}, 8 \mathrm{~B}$, and $8 \mathrm{C}$ ). Furthermore, the effect of PBN on $\mathrm{MJ}$-decreased $\mathrm{AsA}$ and GSH contents could be reversed by C-PTIO (Figs. 8D and 8E). Clearly, the effect of NO donor $\mathrm{PBN}$ is attributable to NO released.

\section{Discussion}

Jasmonates have both chemical and physiological similarities to abscisic acid (Anderson et al. 1989). Since endogenous 
Figure 3. Changes in the activities of $\operatorname{APOD}(A), G R$ $(B), C A T(C)$, and POD (D) in rice leaves treated with MJ. Detached rice leaves were treated with either water or $45 \mu \mathrm{mol} \mathrm{L}{ }^{-1} \mathrm{MJ}$ in the dark. Data are means $( \pm \mathrm{SE})$ of four replicates of a single typical experiment. Three series of independent experiments were carried out giving reproducible results.

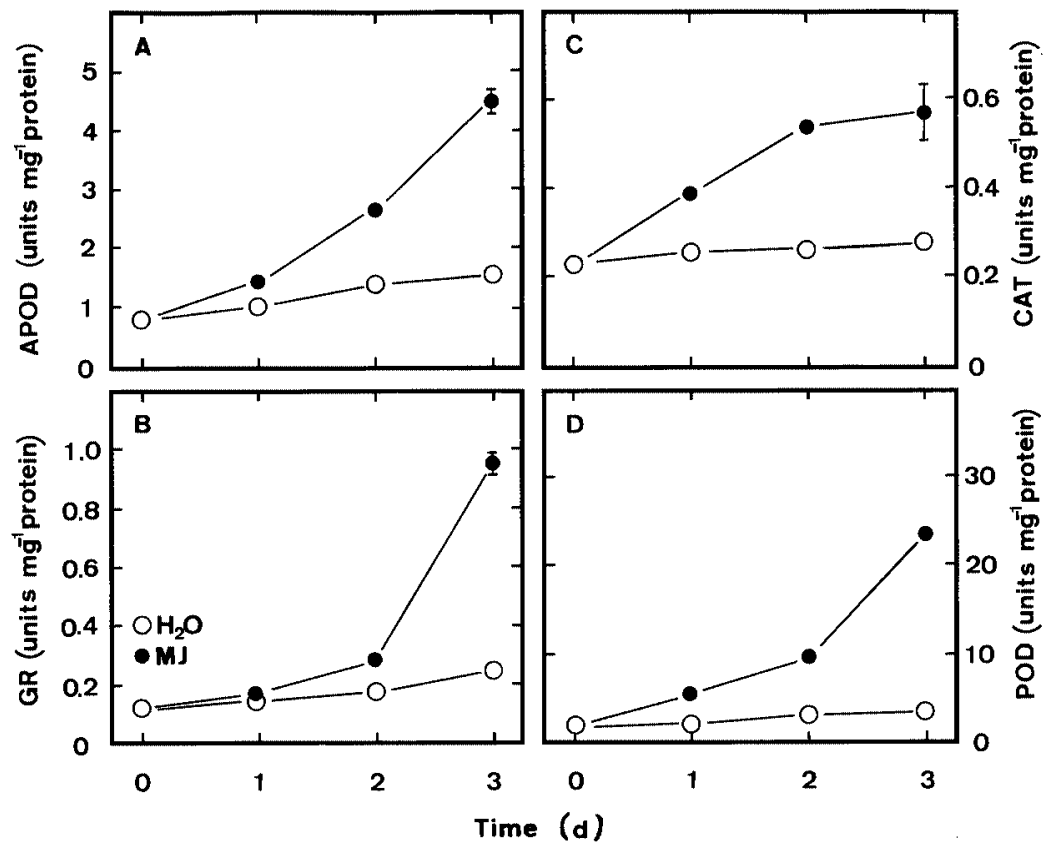

It has been shown that MJ can cause an increased production of $\mathrm{H}_{2} \mathrm{O}_{2}$ (Orozco-Cárdenas and Ryan 1999) and induce lipid peroxidation (Hung and Kao 1998). These suggest that MJ treatment causes oxidative stress in plants. Our results not only have shown that $\mathrm{MJ}$ increased the content of $\mathrm{H}_{2} \mathrm{O}_{2}$ (Fig. $1 \mathrm{C}$ ) and the activities of APOD (Fig. $3 \mathrm{~A}$ ), GR (Fig. 3B), CAT (Fig. 3C), and POD (Fig. 3D), but also demonstrate that $\mathrm{MJ}$ caused a decrease in AsA (Fig. 4A) and GSH contents (Fig. 4B). Meanwhile, protein loss (Fig. 1A) and lipid peroxidation (Fig. 1B) were observed in MJ-treated rice leaves. All these results suggest that MJ causes oxidative stress and that MJ-promoted senescence of rice leaves is mediated through oxidative stress. This suggestion is further supported by the observations that free radical scavengers (SB and GSH) inhibit MJ-induced senescence (Fig. 2A), MJincreased lipid peroxidation (Fig. $2 \mathrm{~B}$ ) and $\mathrm{H}_{2} \mathrm{O}_{2}$ content (Fig. $2 \mathrm{C}$ ), MJ-increased antioxidative enzyme activities (Figs. $5 \mathrm{~A}, 5 \mathrm{~B}$, and $5 \mathrm{C}$ ), and MJ-decreased antioxidants (Figs. 5D and 5E).

There is only limited information about the mechanism of MJ-induced $\mathrm{H}_{2} \mathrm{O}_{2}$ production. In several model systems investigated in plants, the accumulation of $\mathrm{H}_{2} \mathrm{O}_{2}$ appears to be mediated by the activation of a membrane-bound NADPH oxidase complex (Orozco-Cárdenas and Ryan 1999, Pei et al. 2000, Zhang et al. 2001, Jiang and Zhang 2002). Our unpublished observations indicate that diphenyleneiodonium chloride and imidazole, inhibitors of NADPH oxidase (Cross 1990, Pei et al. 2000), prevented $\mathrm{MJ}$-induced $\mathrm{H}_{2} \mathrm{O}_{2}$ production, MJpromoted senescence, $\mathrm{MJ}$-increased antioxidative enzyme activities and MJ-decreased antioxidants in rice leaves. Similar results were obtained by using dimethylthiourea, a chemical trap for $\mathrm{H}_{2} \mathrm{O}_{2}$ (unpublished data). Here, we show that MJ abscisic acid content decreased in MJ-treated rice leaves (Wang and Kao 1999), it is unlikely that the effect of MJ on promoting senescence of rice is mediated through abscisic acid.
Figure 4. Changes in the contents of $A s A(A)$ and $G S H(B)$ in rice water or $45 \mathrm{mmolL}^{-1} \mathrm{MJ}$ in the dark. Data are means ( $+\mathrm{SE}$ ) of four replicates of a single typical experiment. Three series of independent experiments were carried out giving reproducible results.
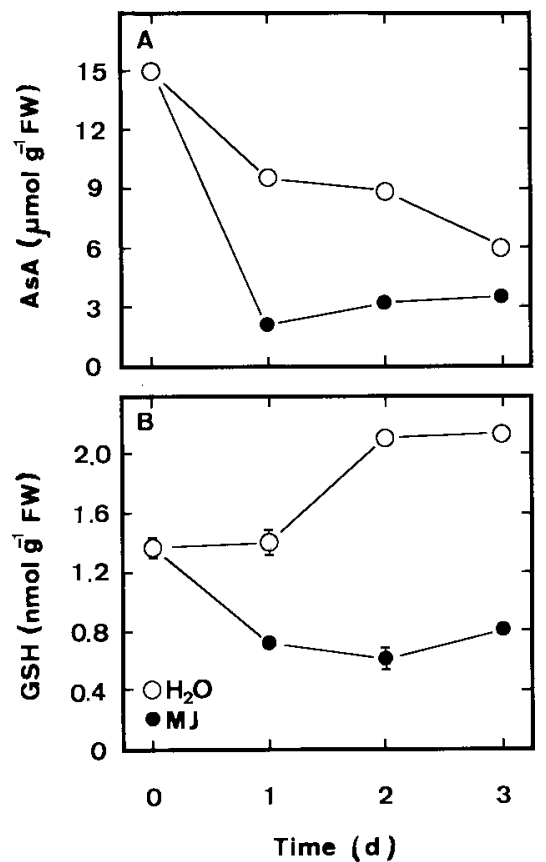


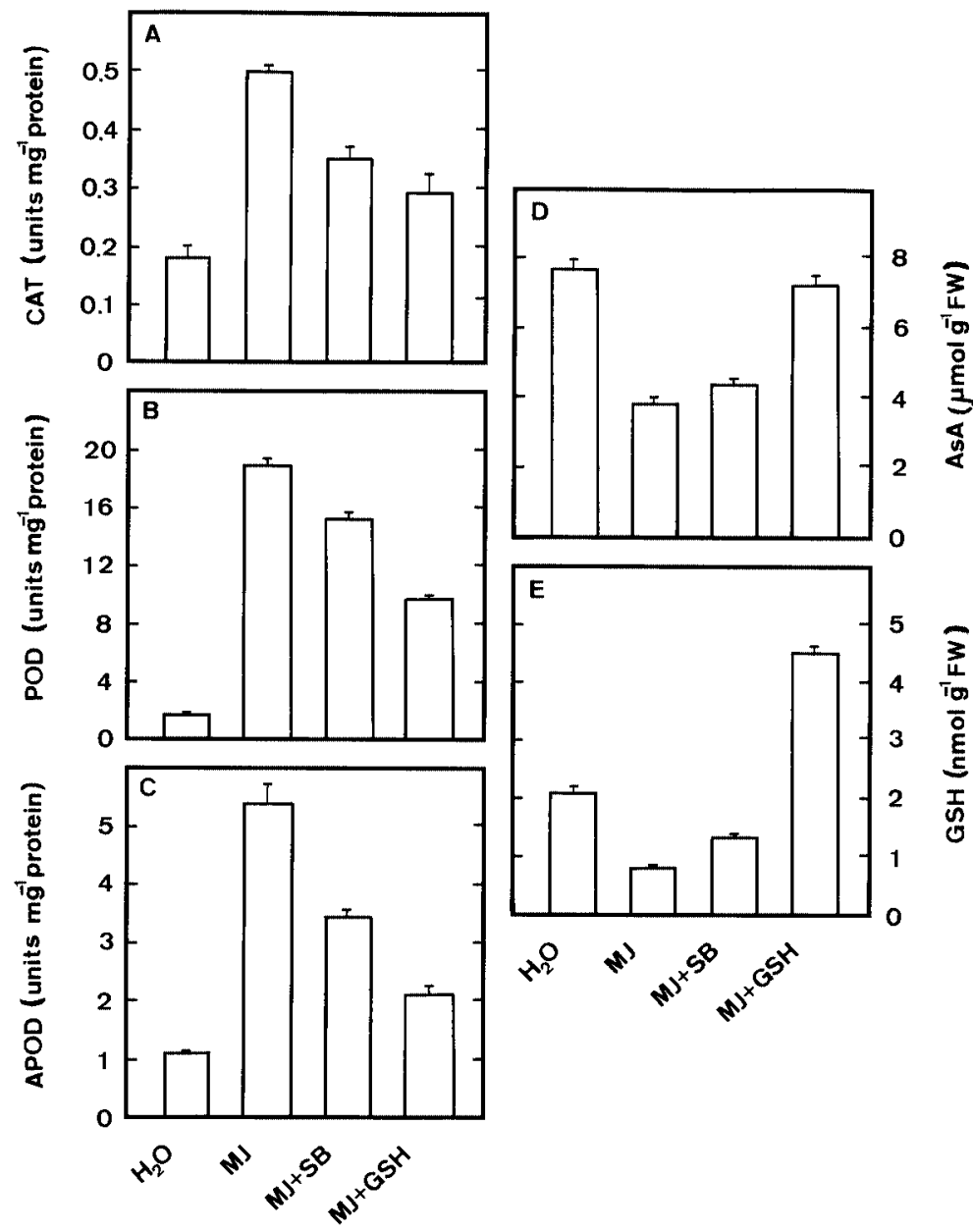

Figure 5. Effect of free radical scavengers on the activities of antioxidative enzymes [CAT (A), POD (B), and APOD $(C)$ and the contents of AsA (D) and GSH (E) in rice leaves treated with $\mathrm{MJ}$. The concentrations of $\mathrm{MJ}, \mathrm{SB}$, and GSH were $45 \mu \mathrm{mol} \mathrm{L}{ }^{-1}, 10 \mathrm{mmol} \mathrm{L}^{-1}$, and $30 \mathrm{mmol} \mathrm{L}^{-1}$, respectively. All measurements were determined 3 days after treatment in the dark. Data are means ( \pm SE) of four replicates of a single typical experiment. Three series of independent experiments were carried out giving reproducible results.

caused the increase in $\mathrm{H}_{2} \mathrm{O}_{2}$ content in rice leaves (Fig. $1 \mathrm{C}$ ). In a short term experiment, we also observed that the increase in $\mathrm{H}_{2} \mathrm{O}_{2}$ content caused by $\mathrm{MJ}$ preceded the de-

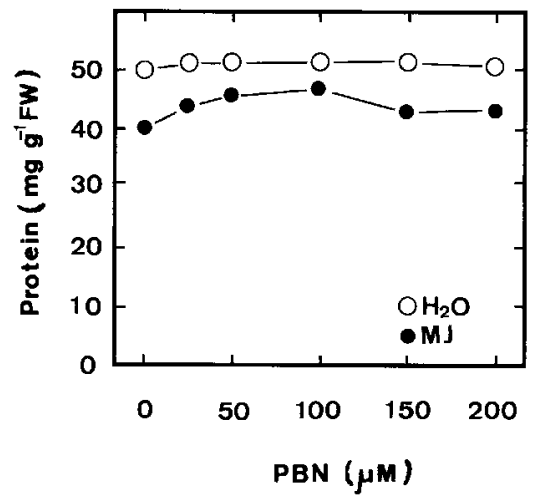

Figure 6. Effect of PBN concentrations on protein contents of rice leaves treated with MJ. Detached rice leaves were treated with either water or $45 \mu \mathrm{mol} \mathrm{L}^{-1} \mathrm{MJ}$ for 1 day in the dark. Data are means ( $\pm \mathrm{SE}$ ) of four replicates of a single typical experiment. Three series of independent experiments were carried out giving reproducible results. crease in protein content and increase in MDA content (unpublished data). It appears that $\mathrm{H}_{2} \mathrm{O}_{2}$ is a key signaling molecule involved in $\mathrm{MJ}$-induced senescence of rice leaves.

AsA is a major antioxidant in photosynthetic and nonphotosynthetic tissues which reacts directly with $\mathrm{AOS}$ and is utilized as a substrate for APOD-catalysed $\mathrm{H}_{2} \mathrm{O}_{2}$ detoxicfication (Noctor and Foyer 1998). GSH is involved in AsA regeneration and functions also as a direct antioxidant of AOS (Noctor and Foyer 1998). Elevated AsA and GSH contents have been measured in plants subjected to abiotic stress (May et al. 1998, Kocsy et al. 2001, Khan et al. 2002, Ruiz and Blumwald 2002). However, there are other reports indicating that AsA and GSH levels decreased in plants in response to abiotic stress (Boo and Jung 1999, Hernandez et al. 2000, Shalta et al. 2001). In the present investigation, we observed that $\mathrm{MJ}$ treatment resulted in decreased $\mathrm{AsA}$ and $\mathrm{GSH}$ in rice leaves (Figs. 4A and 4B). We made the same observation for $\mathrm{H}_{2} \mathrm{O}_{2}$ (unpublished data). The decrease in AsA and GSH contents in rice leaves treated with $\mathrm{MJ}$ is believed to be the result of impaired AsA and GSH metabolism.

It has been suggested that $\mathrm{NO}$ is an antioxidant in plants and its action may be explained by its ability to scavenge AOS (Beligni and Lamattina 1999 a, b, 2002, Cheng et al. 

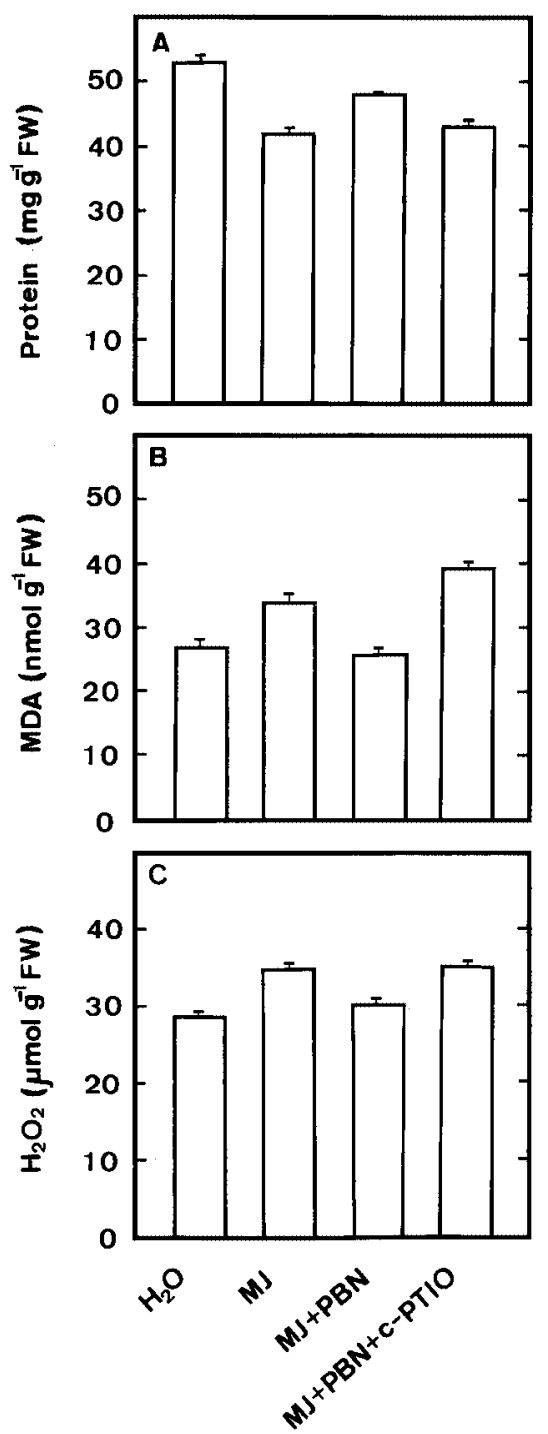

Figure 7. Effect of PBN on protein (A), MDA (B), and $\mathrm{H}_{2} \mathrm{O}_{2}(C)$ contents in MJ-treated rice leaves in the presence or absence of C-PTIO. The concentrations of MJ, PBN, and C-PTIO were 45, 100, and $100 \mu \mathrm{mol} \mathrm{L}^{-1}$, respectively. All measurements were determined 1 day after treatment in the dark. Data are means $( \pm S E)$ of four replicates of a single typical experiment. Three series of independent experiments were carried out giving reproducible results.

2002, Hung et al. 2002, Hung and Kao 2003). If NO acts as an antioxidant, NO may reduce AOS levels in MJ-treated rice leaves. Since $\mathrm{H}_{2} \mathrm{O}_{2}$ is involved in MJ-induced senescence of rice leaves (Fig. $1 \mathrm{C}$ and unpublished data) and $\mathrm{NO}$ reduces MJ-increased $\mathrm{H}_{2} \mathrm{O}_{2}$ content (Fig. $7 \mathrm{C}$ ), it appears that $\mathrm{NO}$ indeed has the ability to scavenge AOS. Orozco-Cárdenas and Ryan (2002) also reported that $\mathrm{NO}$ blocked the $\mathrm{H}_{2} \mathrm{O}_{2}$ production that was induced by jasmonic acid.
In the present investigation, we found that NO reduced $\mathrm{MJ}$ increased MDA content (Fig. 7B) and antioxidative enzyme activities (Figs. 8A, 8B, and 8C) in rice leaves. These results are in agreement with our previous work, in which we demonstrated that NO counteracted paraquat-increased MDA content and antioxidative enzyme activities (Hung et al. 2002). Because lipid peroxidation and the increase in antioxidative enzyme activities are the consequence of AOS overproduction (Kellogg and Fridovich 1975, Thompson et al. 1987) and since $\mathrm{NO}$ acts as an AOS scavenger, the reduction of MDA content and antioxidative enzyme activities could be a result of low levels of $\mathrm{H}_{2} \mathrm{O}_{2}$ in rice leaves treated with $\mathrm{NO}$ and $\mathrm{MJ}$. The fact that $\mathrm{NO}$ counteracts $\mathrm{MJ}$-decreased AsA and $\mathrm{GSH}$ (Figs. 8D and $8 \mathrm{E}$ ) results in an increase in the capacity of $\mathrm{NO}$ to scavenge $\mathrm{H}_{2} \mathrm{O}_{2}$ in rice leaves treated with $\mathrm{NO}$ and $\mathrm{MJ}$ compared to rice leaves treated with $\mathrm{MJ}$ alone and might account in part for the decreased contents of $\mathrm{H}_{2} \mathrm{O}_{2}$ observed in rice leaves treated with $\mathrm{NO}$ and $\mathrm{MJ}$ (Fig. $7 \mathrm{C}$ ).

CAT, APOD, and POD have been shown to be directly inhibited by NO (Ferrer and Barceló 1999, Clark et al. 2000). However, our results show that PBN treatment alone did not affect antioxidative enzyme activities in rice leaves (data not shown). Thus it is unlikely that the reduction of MJ-induced increase in antioxidative enzyme activities by NO is due to a direct NO-mediated inhibition of the enzymes.

In animals, NO displays cytotoxic activity but may also play a cytoprotective role in oxidative stress (Kroncke et al. 1997). In plants that the combination of NO with AOS is also described as either toxic or protective depending on the circumstances (Beligni and Lamattina 1999 c, 2001). AOS can react with NO to form peroxynitrite (Kim and Han 2000, Martinez et al. 2000), which is often thought to have cytotoxic effects (Huie and Padmaja 1993, Alamillo and Garcia-Olmedo 2001, Beligni and Lamattina 2001). Proxynitrite has been shown to react with $\mathrm{H}_{2} \mathrm{O}_{2}$ to yield nitrite ion and oxygen (Martinez et al. 2000). This reaction has been suggested to be the mechanism of NO cytoprotection in animals (Wink et al. 1993). Based on our results, it appears that this mechanism is operating in rice leaves as well.

Previously, we have shown that NO counteracts oxidative stress in rice leaves induced by paraquat, dehydration, polyethylene glycol, and abscisic acid (Cheng et al. 2002, Hung et al. 2002, Hung and Kao 2003). Herein, we report that NO donors act similarly as free radical scavengers (SB and GSH) in inhibiting MJ-promoted rice leaf senescence. These results strongly suggest that the antioxidant properties of $\mathrm{NO}$ are counteracting oxidative stress.

Acknowledgements. This work was supported by grant NSC 902313-B-002-267 from the National Science Council of the Republic of China. 


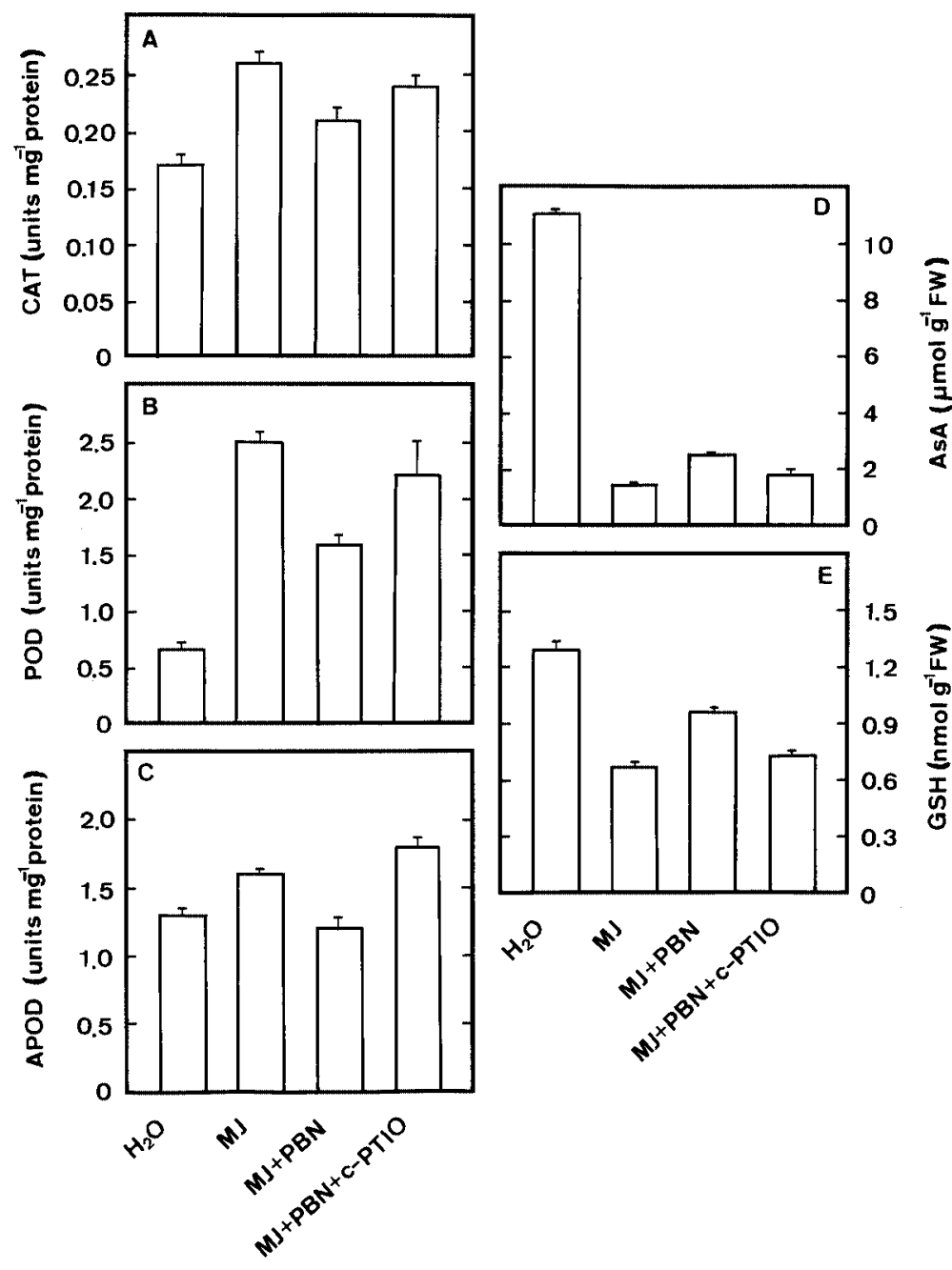

Figure 8. Effect of PBN on the activities of antioxidative enzymes [CAT (A), POD (B), APOD (C)] and the contents of AsA (D) and GSH (E) in MJ-treated rice leaves in the presence or absence of C-PTIO. The concentrations of MJ, PBN, and c-PTIO were 45,100 , and $100 \mu \mathrm{mol} \mathrm{L}^{-1}$, respectively. All measurements were determined 1 day after treatment in the dark. Data are means $( \pm S E)$ of four replicates of a single typical experiment. Three series of independent experiments were carried out giving reproducible results.

\section{References}

Alamillo JM, Garcia-Olmedo F (2001) Effect of urate, a natural inhibitor of peroxynitrite mediated toxicity, in the response of Arabidopsis thaliana to the bacterial pathogen Pseudomonas syringae. Plant $\mathrm{J}$ 25: $529-540$

Anbar M (1995) Nitric oxide: a synchronizing chemical messenger. Experientia 51: $545-550$

Anderson JM, Spilatro SR, Klauer SF, Franceschi VR (1989) Jasmonic acid-dependent increase in the level of vegetative storage proteins in soybean. Plant Sci 62: 45-52

Beligni MV, Lamattina L (1999 a) Nitric oxide counteracts cytotoxic processes mediated by reactive oxygen species in plant tissues. Planta 208: 337-344

Beligni MV, Lamattina L (1999 b) Nitric oxide protects against cellular damage produced by methyl violgen herbicides in potato plants. Nitric Oxide Biol Chem 3: 199-208

Beligni MV, Lamattina L (1999 c) Is nitric oxide toxic or protective? Trends Plant Sci 4: 199-200

Beligni MV, Lamattina L (2000) Nitric oxide stimulates seed germination and de-etiolation, and inhibits hypocotyls elongation, three light-inducible responses in plants. Planta 210: 215-221
Beligni MV, Lamattina L (2001) Nitric oxide in plants: the history is just beginning. Plant Cell Environ 24: 267-278

Beligni MV, Lamattina L (2002) Nitric oxide interferes with plant photooxidative stress by detoxifying reactive oxygen species. Plant Cell Environ 25: 737-748

Beligni MV, Fath A, Bethake PC, Lamattina L, Jones RL (2002) Nitric oxide acts as an antioxidant and delays programmed cell death in barley aleurone layers. Plant Physiol 129: 1462-1650

Boo YH, Jung J (1999) Water deficit-induced oxidative stress and antioxidative defenses in rice plants. J Plant Physiol 155: 255-261

Bradford MM (1976) A rapid and sensitive method for the quantitation of microgram quantities of protein utilizing the principle of proteindye binding. Anal Biochem 72: 248-254

Chen SJ, Kao CH (1998) Methyl jasmonate, ammonium, and leaf senescence in rice. J Plant Physiol 152: 353-357

Cheng F-Y, Hsu S-Y, Kao CH (2002) Nitric oxide counteracts the senescence of detached rice leaves induced by dehydration and polyethylene glycol but not by sorbitol. Plant Growth Regul 38: 265-272

Chou CM, Kao CH (1992) Methyl jasmonate, calcium and leaf senescence in rice. Plant Physiol 99: 1693-1694 
Chu C, Lee TM (1989) The relationship between ethylene biosynthesis and chilling tolerance in seedlings of rice (Oryza sativa). Bot Bull Acad Sin 30: 263-273

Clark D, Dunar J, Navarre DA, Klessig DF (2000) Nitric oxide inhibition of tobacco catalase and ascorbate peroxidase. Mol Plant-Microbe Interact 13: 1380-1384

Creelman RA, Mullet JE (1997) Biosynthesis and action of jasmonates in plants. Annu Rev Plant Physiol Plant Mol Biol 48: 355-381

Cross AR (1990) Inhibitors of leukocyte superoxide generating oxidase: mechanisms of action and methods for their elucidation. Free Radic Biol Med 8: 71-93

Delledonne M, Xia Y, Dixon RA, Lamb C (1998) Nitric oxide functions as a signal in plant disease resistance. Nature 394: 585-588

d'Ischia M, Palumbo A, Buzzo F (2000) Interactions of nitric oxide with lipid peroxidation products under aerobic conditions: Inhibitory effects on the formation of malondialdehyde and related thiobabituric acid-reactive substances. Nitric Oxide Biol Chem 4: 4-14

Ferrer MA, Barceló AR (1999) Differential effects of nitric oxide on peroxidase and $\mathrm{H}_{2} \mathrm{O}_{2}$ production by the xylem of Zinnia elegans. Plant Cell Environ 22: 891-897

Foster JG, Hess JL (1980) Responses of superoxide dismutase and glutathione reductase activities in cotton leaf tissue exposed to an atmosphere enriched in oxygen. Plant Physiol 66: 482-487

Foyer CH, Lopez-Delgado H, Dat JF, Scott IM (1997) Hydrogen peroxide and glutathione-associated mechanism of acclimatory stress tolerance and signaling. Physiol Plant 100: 241-254

Garcia-Mata C, Lamattina L (2002) Nitric oxide and abscisic acid cross talk in guard cells. Plant Physiol 128: 790-792

Graziano M, Beligni MV, Lamattina L (2002) Nitric oxide improves internal iron availability. Plant Physiol 130: 1852-1859

He Y, Fukushige H, Hildebrand DF, Gan S (2002) Evidence supporting a role of jasmonic acid in Arabidopsis leaf senescence. Plant Physiol 128: 876-884

Heath RL, Packer L (1968) Photoperoxidation in isolated chloroplasts. I. Kinetics and stoichiometry of fatty acid peroxidation. Arch Biochem Biophys 125: 189-198

Hernandez JA, Jimenez A, Mullineaux P, Sevilla F (2000) Tolerance of pea (Pisum sativum L.) to long-term salt stress is associated with induction of antioxidant defenses. Plant Cell Environ 23: 853-862

Huie RE, Padmaja S (1993) The reaction of $\mathrm{NO}$ with $\mathrm{O}_{2}{ }^{-}$. Free Radic Res Commun 235: 264-267

Hung KT, Kao CH (1998) Involvement of lipid peroxidation in methyl jasmonate-promoted senescence in detached rice leaves. Plant Growth Regul 24: 17-21

Hung KT, Kao CH (2003) Nitric oxide counteracts the senescence of rice leaves induced by abscisic acid. J Plant Physiol 160: 871-879

Hung KT, Chang CJ, Kao CH (2002) Paraquat toxicity is reduced by nitric oxide in rice leaves. J Plant Physiol 159: 159-166

Jana S, Choudhuri MA (1981) Glycolate metabolism of three submerged aquatic angiosperm during aging. Aquat Bot 12: 345-354

Jiang M, Zhang J (2002) Involvement of plasma membrane NADPH oxidase in abscisic acid- and water stress-induced antioxidant defense in leaves of maize seedlings. Planta 215: 1022-1030

Kao CH (1980) Senescence of rice leaves IV. Influence of benzyladenine on chlorophyll degradation. Plant Cell Physiol 21: 1255-1262

Kato M, Shimizu S (1987) Chlorophyll metabolism in higher plants. VII. Chlorophyll degradation in higher pants. VII. Chlorophyll degradation in senescing tobacco leaves: Phenolic-dependent peroxidative degradation. Can J Bot 65: 729-735
Kellogg EW, Fridovich I (1975) Superoxide, hydrogen peroxide, and singlet oxygen in lipid peroxidation by xanthine oxidase system. $J$ Biol Chem 250: 8812-8817

Khan MH, Singha KLB, Panda SK (2002) Changes in antioxidant level in Oryza sativa L. roots subjected to $\mathrm{NaCl}$-salinity stress. Acta Physiol Plant 24: 145-148

Kim YS, Han S (2000) Nitric oxide protects Cu, Zn-superoxide dismutase from hydrogen peroxide-induced inactivation. FEBS Lett 479: $25-28$

Klessig DF, Durner J, Noad R, Navarre DA, Wendehenne D, Kumar D, Zhou JM, Shah J, Zhaud S, Kachroo P, Trifa Y, Pontier D, Lam E, Silva $H(2000)$ Nitric oxide and salicylic acid signaling in plant defense. Proc Natl Acad Sci USA 97: 8849-8855

Kocsy G, Galiba G, Brunvld C (2001) Role of glutathione in adaptation and signalling during chilling and cold acclimation in plants. Physiol Plant 113: 158-164

Kroncke K-D, Fehsel K, Kolb-Bachofen V (1997) Nitric oxide: Cytotoxicity versus cytoprotection- how, why, when, and where? Nitric Oxide Biol Chem 2: 107-120

Lamattina L, Garcia-Mata C, Graziano M, Pagnussat G (2003) Nitric oxide: the versatility of an extensive signal molecule. Annu Rev Plant Biol 54: 109-136

Laws MY, Charles SA, Halliwell B (1983) Glutathione and ascorbic acid in spinach chloroplasts: the effect of hydrogen peroxide and of paraquat. Biochem J 210: 899-903

Leshem YY (2000) Nitric Oxide in Plants. Occurrence, Function and Use. Kluwer Academic Publishers, Dordrecht

Leshem YY, Haramaty E (1996) Plant aging: the emission of NO and ethylene and effect of NO-releasing compounds on growth of pea (Pisum sativum) foliage. J Plant Physiol 148: 258-263

MacAdam JW, Nelson CJ, Sharp RE (1992) Peroxidase activity in the leaf elongation zone of tall fescue. Plant Physiol 99: 872-878

Martinez GR, DiMascio P, Bonini MG, Augusto O, Briviba K, Sies H, Mauer P, Röthlisberger U, Herold S, Koppenol WH (2000) Peroxynitrite does not decompose to singlet oxygen $\left({ }^{\prime} \Delta g \mathrm{O}_{2}\right)$ and nitroxyl $\left(\mathrm{NO}^{-}\right)$. Proc Natl Acad Sci USA 97: 10307-10312

May MJ, Vernoux T, Leaver C, Van Montagu M, Inzé D (1998) Glutathione homeostasis in palnts: implications for environmental sensing and plant development. J Exp Bot 49: 649-667

Meyer A, Miersch O, Buttner C, Dathe W, Sembdner G (1991) Occurrence of the plant growth regulator jasmonic acid in plants. J Plant Growth Regul 3: 1-8

Nakano Y, Asada K (1981) Hydrogen peroxide is scavenged by ascorbate-specific peroxidase in spinach chloroplasts. Plant Cell Physiol 22: $867-880$

Neill SJ, Desikan R, Clarke A, Hancock JT (2002) Nitric oxide is a novel component of abscisic acid signaling in stomatal guard cells. Plant Physiol 128: 13-16

Noctor G, Foyer CH (1998) Ascorbate and glutathione: keeping active oxygen under control. Annu Rev Plant Physiol Plant Mol Biol 49 249-279

Noritake T, Kawakita K, Doke N (1996) Nitric oxide induces phytoalexin accumulation in potato tuber tissues. Plant Cell Physiol 37: 113116

O'Donnell VB, Chunley PH, Hogg N, Bloodsworth A, Darley-Usmar VM, Freeman BA (1997) Nitric oxide inhibition of lipid peroxidation: Kinetics of reaction with lipid peroxyl radicals and comparison with $\alpha$-tocopherol. Biochemistry 36: 15216-15223 
Orozco-Cárdenas M, Ryan CA (1999) Hydrogen peroxide is generated systemically in plant leaves by wounding and systemin via the octadecanoid pathway. Proc Natl Acad Sci USA 96: 6553-6557

Orozco-Cárdenas M, Ryan CA (2002) Nitric oxide negatively modulate wound signaling in tomato plants. Plant Physiol 130: 487-493

Orozco-Cárdenas M, Narváez-Vásquez J, Ryan CA (2001) Hydrogen peroxide acts as a second messenger for the induction of defense genes in tomato plants in response to wounding, systemin, and methyl jasmonate. Plant Cell 13: 179-191

Pagnussat GC, Simontacchi M, Puntarulo S, Lamattina L (2002) Nitric oxide is required for root organogenesis. Plant Physiol 129: 954 956

Paoletti F, Aldinucci D, Mocali A, Capparini A (1986) A sensitive spectrophotometric method for the determination of superoxide dismutase activity in tissue extracts. Anal Biochem 154: 536-541

Pedroso MC, Magalhases JR, Durzan D (2000) Nitric oxide induces cell death in Taxus cells. Plant Sci 157: 173-180

Pei ZM, Murata N, Benning G, Thomine S, Klüsener B, Allen GJ, Grill E, Schroeder JI (2000) Calcium channels activated by hydrogen peroxide mediate abscisic acid signaling in guard cells. Nature 406: 731-734

Ruiz JM, Blumwald E (2002) Salinity-induced glutathione synthesis in Brassica napus. Planta 214: 965-969

Scherer GFE, Holk A (2000) NO donors mimic and NO inhibitors inhibit cytokinin action in betaine accumulation in Amaranthus caudatus. Plant Growth Regul 32: 345-350

Sembdner G, Parthier B (1993) The biochemistry and the physiological and molecular actions of jasmonates. Annu Rev Plant Physiol Plant Mol Biol 44: 569-589

Shalta A, Mittova V, Volokita M, Guy M, Tal M (2001) Response of the cultivated tomato and its wild salt-tolerant relative Lycopericon pennellii to salt-dependent oxidative stress: the root antioxidative system. Physiol Plant 112: 487-494
Smith IK (1985) Stimulation of glutathione synthesis in photorespiring plants by catalase inhibitors. Plant Physiol 79: 1044-1047

Strother S (1988) The role of free radicals in leaf senescence. Gerontology 34: 151-156

Thompson JE, Legge RL, Barber RF (1987) The role of free radical in senescence and wounding. New Phytol 105: 317-344

Tsai FY, Hung KT, Kao CH (1996) An increase in ethylene sensitivity is associated with jasmonate-promoted senescence of detached rice leaves. J Plant Growth Regul 15: 197-200

Uchida A, Jagendorf AT, Hibino T, Takabe T (2002) Effects of hydrogen peroxide and nitric oxide on both salt and heat stress tolerance in rice. Plant Sci 163: 515-523

Ueda J, Kato J (1981) Promotive effect of methyl jasmonate on oat leaf senescence in the light. Z Pflanzenphysiol 103: 357-359

Wang J-W, Kao CH (1999) Endogenous abscisic acid levels are not linked to methyl jasmonate-promoted senescence of detached rice leaves. Plant Growth Regul 28: 17-20

Wasternack C, Parthier B (1997) Jasmonate-signalled plant gene expression. Trends Plant Sci 2: 302-307

Weidhase RA, Lehmann J, Kramell H, Sembdner G, Parthier B (1987) Degradation of ribulsoe-1,5-bisphosphate carboxylase and chlorophyll in senescing barley leaf segments triggered by jasmonic acid methylester, and counteraction by cytokinin. Physiol Plant 69: 161166

Wink DA, Hanbauer I, Krishna MC, DeGraff W, Gamson J, Mitchell JB (1993) Nitric oxide protects against cellular damage and cytotoxicity from reactive oxygen species. Proc Natl Acad Sci USA 90: 9813-9817

Zhang X, Zhang L, Dong F, Gao J, Galbraite DW, Song C-P (2001) Hydrogen peroxide is involved in abscisic acid-induced stomatal closure in Vicia faba. Plant Physiol 126: 1438-1448 